\title{
BLUETOOTH TECHNOLOGY: AN EXPLORATORY STUDY OF THE ANALYSIS AND IMPLEMENTATION FRAMEWORKS
}

\author{
Akshay Mehta*1, Alok Kumar ${ }^{2}$ \\ ${ }^{* 1,2}$ Department of Computer Science and Engineering, Dronacharya college of engineering, Gurgaon, Haryana
}

\section{*Corresponding Author: -}

\begin{abstract}
: -
Bluetooth is still a relatively new technology to the wireless world. It is designed for wireless communication between a wide variety of different Bluetooth enabled devices; from computers and PDAs to GPS systems and heart monitoring devices. There are a growing number of companies continually adopting this technology. As Bluetooth becomes a standard feature in many products that we use every day, it seems that the use of the technology will grow even faster in the future. This paper provides an analysis of the technology's features and how companies should go about deciding if they should adopt Bluetooth or another wireless alternative. First, the paper talks about what Bluetooth is and how it compares with other wireless standards. It then goes into an analysis of how feasible integrating Bluetooth into a business would be, and how some industries are already using the technology. These case studies are followed by a look at what steps need to be taken through the implementation cycle, and deciding what technology makes a better fit for a business. The paper ends with a look at the pros and cons of Bluetooth, as well as a look into what the future may hold for this technology.
\end{abstract}

Keywords: Bluetooth; Feasibility study; Frequency-hopping spread-spectrum (FHSS); Mobile commerce; Systems analysis and design; Wireless communications

\section{(a) $(\$)$}




\section{INTRODUCTION}

With technology changing at such a rapid pace and the weakened economy, it is hard to determine what is going to become the next dominant technology or just another fad. When computers first came out to the public market, technology was not growing as fast, and there were not many variations in the products from one month to the next, unlike today. There were also new technologies being created on how to inter-connect all these computers. First, they had to be connected by wires and users were confined to limited work areas. More recently, the trend has shifted towards wireless communication because of the freedom that it gives the user to move about without much restriction. In addition, advancements in wireless technology are developing and expanding rapidly. New standards and protocols are being created in order to meet the goal of uniformity and cohesiveness between all technologies. This rapid change can make companies hesitant to choose one technology over the other, because something new may come out very soon to better fit the needs of the company.

Even though it is difficult to predict which tech- nology will last in the future, businesses must strive to stay ahead of the competition and maintain the leading advantage to better meet their own challenges and their customers' needs. One way to stay on the move is to upgrade from a wired system to a wireless system. Many companies have already started engaging in a wireless system, but some are still hesitant because of lack of standards, and more importantly, security issues. There are also many different types of wireless technologies out there to choose from. If a company has made the decision to go wireless, they must decide which technology better fits their needs. With any wireless technology, employees would have the flexibility to facilitate the communication and information access/retrieval with a limited restriction. This could lead to a more productive working envi- ronment, due to fewer, physical location constraints imposed on the employees. One wireless technology that companies should consider is Bluetooth. Bluetooth is relatively new to the wireless era, growing at a rapid pace, showing much promise, and acting to bring more productivity and efficiency to the companies' operation in the future.

This paper gives an overview of what Bluetooth is and how it works. It also explores other wireless technologies and how they measure up to Bluetooth. Some companies and industries have already adopted Bluetooth as their wireless solution. A few of these companies will be discussed, as well as the criteria that other businesses need to look at in order to determine if Bluetooth is the right choice for them.

\subsection{Bluetooth definitions}

Bluetooth is a wireless technology that can be used for short-ranged communication between different Bluetooth enabled devices. Some of its common functions are passing and synchronizing data, such as a PDA and computer, and connecting to the Internet. Bluetooth works in the unlicensed 2.4-GHz industrial, scientific, and medical (ISM) band and uses frequency- hopping spread-spectrum (FHSS) commu-nication, which transmits data over different frequen-cies at different time intervals. This is accomplished by making "hops" to different frequencies through the ISM band. A device makes about 1600 hops per second, which is spaced out over $1 \mathrm{MHz}$ [9].

Unlike most devices, Bluetooth enabled devices communicate with each other automatically. There is no need to specify what type of action to take place or when it should to happen. When two devices are within range of each other, they will communicate back and forth to determine if there is any information to be passed. During initial communication, it is necessary to create a relationship between unknown devices; this process is referred to as pairing. During the paring process, a secret PIN is created that is only known by the two devices that are communicating. It is better for the user to manually enter a PIN, and make it complex, in order to make the code hard to break.

Since Bluetooth is a wireless protocol, anyone with an appropriate receiver can intercept transmissions. In order to reduce hacking, Bluetooth supports device authentication, which means, devices that share infor-mation use a shared secret key, or link key to authenticate one another. If the devices have commu-nicated in the past, they will share a common link key, which can take two forms. The first, and least secure, is a unit key. A unit key is the same secret key for every device that has established a connection. For example, if a PDA and a Mobile Phone exchange information, then later that same PDA and notebook computer share information, all three devices will share the same unit key, leaving them much more accessible to attacks. It is recommended that a unit key only be used for devices with limited memory and limited user interface devices. The second, and much more secure, is a combination key. Combination keys are unique and change each time the devices make a new connection, so no two devices share the same key. Since the keys are different, it is much easier to protect the communication between the devices $[3,25]$.

\subsection{History and evolution}

Bluetooth is named after a Danish king, Harald Bluetooth, who ruled from 940 to 985 AD [9]. During his rein, Bluetooth was able to unite Denmark and part of Norway into a single kingdom. In 1994, Ericsson started researching short-range wireless technology that could be used between their cellular phones and peripheral devices, such as a headset [3]. In 1998, Ericsson, Nokia, IBM, Toshiba, and Intel came to- gether to form a Special Interest Group (SIG). These companies were chosen because of Ericsson and Nokia's leadership in mobile telephones, IBM and Toshiba's leadership in laptop computing, and Intel's leadership in digital signal processing technology. In four short years, the original five companies, in the SIG, have turned into 1500 [20].

Bluetooth's original mission was to replace all of the cables that tie up today's complex world. There are many cables plugged into the back of a computer, for instance, a monitor, a keyboard, a mouse, and a printer. The location of the correct plug can become very confusing for the user, as more "plugged-in", devices are introduced; this is where Bluetooth comes in.

The developers of Bluetooth soon realized that this technology is capable of much more than just con-necting peripheral 
devices. It can work as a lower speed wireless network, allowing connection through access points at any location. Bluetooth is also a universal standard and can be used wherever you go, which makes it extremely powerful.

Some current devices that are not Bluetooth en- abled can add Bluetooth capability via PC cards or USB adaptors. As this technology continues to grow, more and more devices will come with Bluetooth chips built-in. There are many devices on the market that already have Bluetooth built into them, such as phones, laptops, and PDAs. As more of these devices are released to the public, Bluetooth's place in society will be sealed. Table 1 summarized all the discussion above with major milestones and lessons learned in each age.

\subsection{Architecture}

When Bluetooth devices connect with one another, a small network called a piconet is formed. There can be up to eight devices in one piconet at any one time. Even though there is a connection between devices, that connection is not always open to communication. One of the devices in the piconet will take the role of the master and the rest will be slaves. Since Bluetooth uses frequency-hopping spread-spectrum, the slave devices will synchronize their hops along with the master's hops. This will allow the devices to continue to communicate without each device hopping over to different frequencies and losing the connection. Blue- tooth devices will automatically form a connection when they come within range of one another. They can also be set up to automatically synchronize data, such as between a PDA and a computer [9].

If it is necessary for more than eight devices to be involved in a network, piconets can be connected together to form a scatternet. Within each piconet, one device is selected to act as a bridge to another piconet [9].

Table 1:- History and evolution of Bluetooth technology

\begin{tabular}{|c|c|c|c|}
\hline Year & Age & Major milestones & Lessons learned \\
\hline 1996 & Introduction & $\begin{array}{l}\text { Ericsson started research on } \\
\text { a short-range wireless solution } \\
\text { peripheral devices }\end{array}$ & $\begin{array}{l}\text { Bluetooth is capable of much more } \\
\text { than originally expected. }\end{array}$ \\
\hline $1998-2000$ & Growth & $\begin{array}{l}\text { SIG was formed and is } \\
\text { continually growing }\end{array}$ & $\begin{array}{l}\text { Bluetooth is showing what it is } \\
\text { capable } \\
\text { of and with growing support many } \\
\text { more uses are coming into play, but } \\
\text { there is still a need for security. }\end{array}$ \\
\hline $2000-2003$ & Maturity & $\begin{array}{l}\text { Bluetooth is being used in } \\
\text { conjunction with other wireless } \\
\text { standards, such as Wi-Fi }\end{array}$ & $\begin{array}{l}2.4-\mathrm{GHz} \text { band may become too } \\
\text { overcrowded, is there a need for a } \\
\text { new solution? }\end{array}$ \\
\hline 2003 - Current & Current/ Future & $\begin{array}{l}\text { Once Bluetooth has more support } \\
\text { the commercial, and consun } \\
\text { market, prices will begin to drop }\end{array}$ & $\begin{array}{l}\text { Price will not drop until there is more } \\
\text { support and there will not be much } \\
\text { more support until prices drop. }\end{array}$ \\
\hline
\end{tabular}

\subsection{Comparison with other wireless technologies}

There are many ways to create a network between different devices. The following is a short overview of just a few of the wireless technologies available.

\subsubsection{Induction Wireless}

Wireless devices that utilize radio frequencies for data transfer, such as Bluetooth, use an electric and a magnetic field. Induction Wireless, invented by Aura Communications, uses only the magnetic field. Data can only be transmitted within a 3 -m radius at speeds of

204.8 Kbits/s [10]. This short range communication adds extra security, because in order to receive the data, someone would need to be very close to the source. Compared to Bluetooth, Induction Wireless requires lower power consumption and costs less.

\subsubsection{Infrared Wireless}

Infrared Wireless (IrDA) may have been the first personal area network technology used to transfer data over short distances. Most IrDA devices can only transmit up to $1 \mathrm{~m}$; beyond that range, the signal quickly weakens. There are two versions available that have a transfer rate at either 4 or $16 \mathrm{Mbits} / \mathrm{s}$ [10]. In order to transfer data, the sender and receiver must be in line-of-site. This characteristic of IrDA adds an extra security feature that most wireless technologies cannot offer because its signal is not sent out in all directions.

\subsubsection{Ultra Wideband}

Ultra Wideband is fairly new to the commercial and consumer market. Its main use has been for military and government applications, such as short range, high-resolution radar and imaging. Like Blue- tooth, the signal can penetrate walls, but it can be used anywhere in the 3.1- to $10.6-\mathrm{GHz}$ band. It also has an astonishing transfer rate at $100 \mathrm{Mbits} / \mathrm{s}$ [10].

\subsubsection{ZigBee}

Philips created a slower, less expensive, and lower power cousin to Bluetooth, called ZigBee, and has many of the same characteristics of Bluetooth. ZigBee works in the 2.4-GHz band, and uses frequency- hopping spread-spectrum. Unlike 
Bluetooth, it takes 25 hops spaced out over every $4 \mathrm{MHz}$ and transfers data at

$250 \mathrm{Kbits} / \mathrm{s}$. For an extended range of $134 \mathrm{~m}$, and greater reliability, ZigBee can transfer at $28 \mathrm{Kbits} / \mathrm{s}$. It has the capability of attaching up to 254 nodes to one network, but so far there are no chips available to the public [10].

\subsubsection{IEEE 802.11b}

Bluetooth is sometimes confused with another wireless technology, 802.11b. $802.11 \mathrm{~b}$ is a standard specification for wireless LANs, but Bluetooth is capable of so much more. $802.11 \mathrm{~b}$ also work in the $2.4-\mathrm{GHz}$ band, but uses directsequencing spread- spectrum (DSSS), which sends data over several different frequencies simultaneously, instead of individually. Device authentication is also different. $802.11 \mathrm{~b}$ frequently will reuse the packet keys, leaving the devices open to more attacks. $802.11 \mathrm{~b}$ will also use this same key for the authentication process and encryption, whereas Bluetooth uses separate keys for each [10]. Table 2 provides an overview of all different technologies.

\subsection{Bluetooth vendors}

Cambridge Silicon Radio (CSR) and Silicon Wave are two of the largest Bluetooth chip vendors, ship-ping millions of chip sets every year [1]. CSR's main focus is on solutions using Bluetooth personal area networking. They were founded in 1998 with a goal to develop single-chip radio devices. The founders came from Cambridge Consultants, and they continue a development partnership today. CSR also receives

Table 2: - Comparison with other wireless technologies

\begin{tabular}{|c|c|c|c|c|c|c|}
\hline & Bluetooth & $\begin{array}{l}\text { Induction } \\
\text { Wireless }\end{array}$ & IrDA & $\begin{array}{l}\text { Ultra } \\
\text { Wideband }\end{array}$ & Zigbee & $\begin{array}{l}\text { IEEE } \\
802.11 b\end{array}$ \\
\hline $\begin{array}{l}\text { Transmissi } \\
\text { on }\end{array}$ & Radio wave & Magnetic field & Infrared & Radio & Radio & Radio \\
\hline $\begin{array}{l}\text { Operation } \\
\text { frequencies } \\
\text { Sneeds }\end{array}$ & $\begin{array}{l}2.4-\mathrm{GHz} \\
\text { band }\end{array}$ & - & - & $\begin{array}{l}3.1-10.6-\mathrm{GHz} \\
\text { band } \\
100 \mathrm{hit} / \mathrm{s}\end{array}$ & $\begin{array}{l}2.4-\mathrm{GHz} \\
\text { band }\end{array}$ & $\begin{array}{l}2.4-\mathrm{GHz} \\
\text { band }\end{array}$ \\
\hline & $1 \mathrm{Mbit} / \mathrm{s}$ & $204.8 \mathrm{~Kb} 1 \mathrm{t} / \mathrm{s}$ & 4 or 16 Mbit $/ \mathrm{s}$ & & & \\
\hline
\end{tabular}

funding from some of the world's leading venture capital investors, such as, Capital Research, LDC, and Sony [5]. Silicon Wave was founded in 1997 and is based out of San Diego [1]. They manufacture prod-ucts such as Radio processors, Radio Modems, Base-band Processors, and Coexistence Technologies. Silicon Wave is partnered up with 7 Layers Inc. for Bluetooth testing and qualification services [1].

\subsection{Bluetooth pros}

Bluetooth has several advantages, one of the most notable is its ease of use. As with every other wireless technology, Bluetooth frees up the user from being bogged down by wires. With an increasing number of peripheral devices, all the wires can become over- crowded and, at times, confusing. If all the wires and slots are not color-coded, it can become very difficult to figure out the location that each wire gets plugged into, even for a professional. With Bluetooth, all these wires disappear, saving the user the time that would be spent trying to figure out how to get all the devices connected. When two Bluetooth devices come within range of each other, they automatically make a con-nection and decide if there is any information that needs to be passed, or if one needs to control the other.

Not only is the fact that Bluetooth devices use wireless communication an advantage, but also that the communication is done automatically. This reduces user interaction time, and tasks can be accomplished more efficiently. Within a wired environment, if the user wanted two devices to be synchronized, data would either need to be reentered by hand or connect the devices by wires. If the user would forget to do the synchronization, the data would eventually become outdated, and could lead to data discrepancies. Be-cause of the automatic communication between Blue-tooth devices, the user does not need to worry about forgetting to synchronize, so the data between devices would always match and be up-to-date.

Another advantage of Bluetooth is its added secu- rity features. The fact that it is a short-range technol- ogy (about $3 \mathrm{~m}$ ) adds some security in itself, because someone would need to be close to the communicat- ing devices to be able to intercept the signal. As discussed earlier, the authentication process is also much more in-depth and harder to crack than that of other wireless standards.

\subsection{Bluetooth cons}

Even though Bluetooth's short range helps secu- rity, there is still the possibility that someone can intercept the signal. The signal that Bluetooth devi- ces send out is sent in every direction, and can travel through walls. Intercepting the signal could be just as easy as sitting in the next room and listening to someone's conversation. With the increasing speeds of computers, programs and hacking equip-ment can be made to quickly and easily crack any code. With a wired network, a hacker needs to somehow tap into the company's network. This makes it harder for hackers because they need a physical connection, whereas with Bluetooth, all they need is a receiver that can catch the radio signals being sent out. As this technology continues to grow and mature, there will be better security measures, and someday may be as secure as some of the wired technologies.

The short range poses another disadvantage for Bluetooth. Only being able to transmit to distances up to $30 \mathrm{ft}$ away can be very limiting in an office or production setting. Users cannot go too far away from the device that they are 
communicating with without losing the signal. If a company were spread out over separate buildings, Bluetooth would not work without help from another networking technology, such as a wired system.

Another disadvantage of Bluetooth is its speed. Today there is a greater need than ever for fast speeds to transfer large quantities of data. Bluetooth is only capable of transferring at speeds of $1 \mathrm{Mbit} / \mathrm{s}$, but the SIG is working on a newer version that would allow speeds to reach $10 \mathrm{Mbits} / \mathrm{s}$. If companies need to continuously exchange large files, Bluetooth would not work for their demands. Bluetooth is only meant for small amounts of data to be transferred at one time.

\section{Bluetooth: an analysis framework}

When a company is thinking about investing in a new technology, there are many options that must be considered, and Bluetooth is no exception. One of the most important questions that a company must ask is, "Do we need this new technology and is it technically possible to implement at this time?' It is also impor- tant to know if the company has the monetary funds, the time, and the know-how to be able to implement a new technology. It is essential that the technology follows the company's objective. Along with the cost, the solution that a company decides on must be technically feasible. A company should not adopt a new technology that has not proven its usefulness, because support for that technology will not be around very long if it fails. If the technology is available, the company must make sure it is legal and operationally sound for their company. The technology must also be able to be implemented in a reasonable amount of time, allowing demanding tasks to be completed on time. Therefore, the analysis framework of investing Bluetooth is shown in Fig. 1.

\subsection{Technical feasibility}

Bluetooth is a relatively new technology, but is gaining more and more support in the consumer market. One of the first devices used with Bluetooth is a simple headset that allows people to talk on their Bluetooth phones hands-free. Now Bluetooth has broadened its accessibility to be used with PDAs, laptops, cameras, GPS receivers, watches, printers, keyboards, mice, and access servers, to just name a few. The technology is already available and continuing to develop based on the needs of the businesses.

What makes Bluetooth such an important standard is that it is supported world-wide. No matter where you go, if you have a Bluetooth device, it can interact with

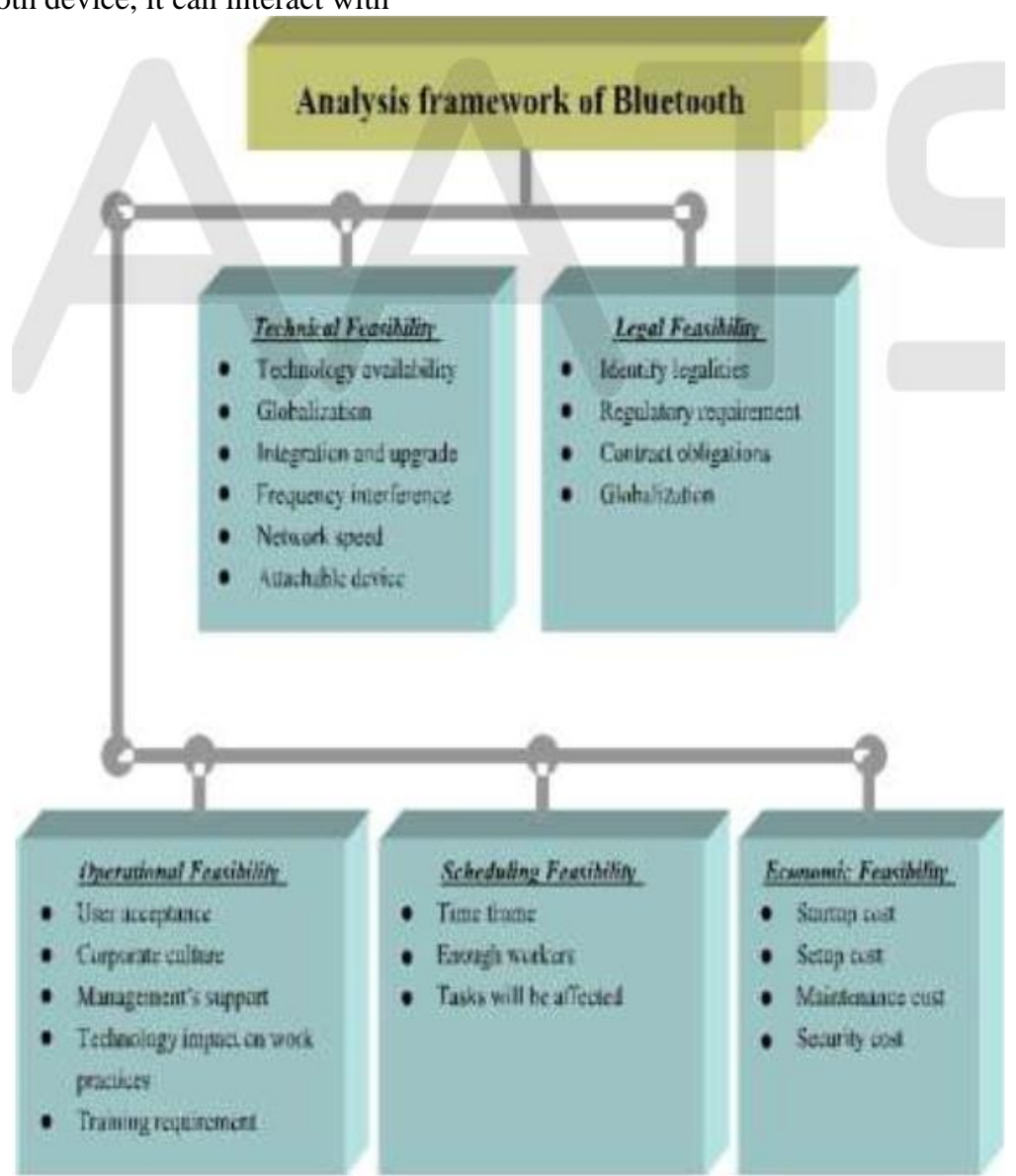

Fig. 1. Analysis framework of Bluetooth.

other Bluetooth devices. This is especially important in today's companies that are continually globalizing.

Bluetooth has been incorporated into many new devices. One concern that may arise is what to do with all the old computers and equipment that do not support Bluetooth; should it all be scrapped? The answer is no. Bluetooth is by no means a cure-all solution, but it can do many useful things. If compa-nies want to start integrating Bluetooth into their current systems, there are ways to upgrade computers and devices into Bluetooth-enabled devices by adding PC cards or USB adaptors. Some phone companies even make Bluetooth adaptors for phones. Another concern is the interference with other wireless devices that work on the same 2.4- GHz band. Although there are collisions that happen from time to time, because of Bluetooth's frequency hopping, interference does not pose a big threat. More collisions occur between 
Bluetooth and the 802.11 standards than any other devices that work in the $2.4-\mathrm{GHz}$ frequency range. Using a separate antenna for each standard will help reduce the collisions and make operations safe from three or more ft apart.

Bluetooth is also not meant for high-speed access. As of now, it can only transfer at speeds up to $1 \mathrm{Mbit} / \mathrm{s}$. It can also only attach up to eight devices to one piconet at a time [9]. For companies that need faster data access and more device support, Bluetooth may not be the solution for them.

\subsection{Economic feasibility}

Another major concern companies have about applying a new technology is the startup cost. Most businesses today have some type of wired network setup and want to postpone adopting a new network- ing scheme in order to see where the wireless world is headed.

Wireless networks can, however, reduce costs because of less maintenance and setup costs. With a wired network, many cables need to be purchased and installed, which can become very expensive. There are also maintenance costs to keep all the wires in good working conditions. If a wire were to acciden-tally get snapped or kicked out of the correct socket, it can take time to get someone to come and fix the problem. With wireless, all these costs are eliminated, except for some maintenance. There are no longer any cables to buy or install, and much of the maintenance costs are decreased because there is not much more to maintain than the interface cards and access points.

The companies that have invested in the production of Bluetooth chips want to have the cost of a single chip down to \$5. Right now the price range is hovering between $\$ 20$ and $\$ 30$ and will not be able to get down to the target price until Bluetooth has a wider accep- tance and the chips are being mass produced [20]. If the $\$ 5$ mark is attainable in the near future, many more companies will most likely invest in Bluetooth because of its accessibility and cheap cost to implement.

One area where cost will be high is security. Since there is no physical barrier to protect systems, keeping hackers from intercepting data will be harder than ever. It is estimated that security cost will be where most money is spent when implementing a wireless network.

\subsection{Legal feasibility}

It is important for any business to identify legalities or any other regulatory requirements they have. This is important in order for the company to assess their capability of meeting these requirements. By doing further investigations of a company, they can find where they are legally liable and should take caution, such as with contract obligations.

The security of Bluetooth is not to be taken lightly, and is the area of most concern. Bluetooth certifica-tion does not require high-level security and interop-erability between products, so the user interfaces, default configurations, and usability choices are left to the manufacturer. This can cause many problems with Bluetooth devices between manufacturers that are not compatible, and safeguards against data cor-ruption and theft can be at a minimum.

Since Bluetooth is also a worldwide standard, business practices and laws of other countries need to be taken into consideration when setting up a network for a global company. If policies of other countries are not followed, a business may lose market share in a country, or even be kicked out and no longer be able to operate within that country.

\section{References}

[1].Anonymous, About Silicon Wave, http://www.siliconwave.com/about.html, April 4, 2003.

[2].Anonymous, Bluetooth and Hotel, 2000 http://www.bluetooth.org.cn/news/e_bluehotel.htm, Feb. 14, 2003.

[3].Anonymous, Bluetooth Wireless Technology Enhances Appli- cations for Mobil Telephony, Business Wire, Feb. 21, 2002,http://www.findarticles.com/cf_0/m0EIN/2002_Feb_21/83104934/p1/article.jhtml?term=bluetooth+wireless+ technology+enhances+applications+for+mobil+telephony, Feb. 15, 2003. 